\title{
Dynamics of insulin secretion and the clinical implications for obesity and diabetes
}

\author{
Susumu Seino, ${ }^{1,2,3}$ Tadao Shibasaki, $^{2}$ and Kohtaro Minami ${ }^{2}$ \\ 1Division of Diabetes and Endocrinology, Department of Internal Medicine, and 2Division of Cellular and Molecular Medicine, \\ Department of Physiology and Cell Biology, Kobe University Graduate School of Medicine, Kobe, Japan. \\ ${ }^{3}$ Core Research for Evolutional Science and Technology (CREST), Japan Science and Technology Agency, Saitama, Japan.
}

\begin{abstract}
Insulin secretion is a highly dynamic process regulated by various factors including nutrients, hormones, and neuronal inputs. The dynamics of insulin secretion can be studied at different levels: the single $\beta$ cell, pancreatic islet, whole pancreas, and the intact organism. Studies have begun to analyze cellular and molecular mechanisms underlying dynamics of insulin secretion. This review focuses on our current understanding of the dynamics of insulin secretion in vitro and in vivo and discusses their clinical relevance.
\end{abstract}

\section{Introduction}

Insulin, which is secreted from pancreatic $\beta$ cells, is the key hormone in regulating glucose metabolism. Insulin secretion is a highly dynamic process regulated by complex mechanisms. It is regulated by nutrient status, hormonal factors such as gastrointestinal hormone incretins (i.e., glucagon-like peptide 1 [GLP-1] and glucose-dependent insulinotropic polypeptide [GIP; originally termed "gastric inhibitory polypeptide"]), and neural factors (1-5). In addition, the regulation of insulin secretion is a multi-tiered process, occurring at the level of the single $\beta$ cell, the pancreatic islet, the whole pancreas, and the intact organism. Thus, in vivo, the dynamics of insulin secretion is the consequence of an integration of all of these systems.

\section{Fundamental mechanism of insulin secretion}

Stimulus-secretion coupling is an essential biologic event in pancreatic $\beta$ cells. $\mathrm{Ca}^{2+}$, ATP, cAMP, and phospholipid-derived signals such as diacylglycerol and inositol 1,4,5-triphosphate are the major intracellular signals in insulin secretion $(6,7)$. Glucose-stimulated insulin secretion (GSIS) is the principal mechanism of insulin secretion. Glucose is transported into the $\beta$ cell by glucose transporters, and then metabolized, leading to increases in the ATP concentration (or ATP/ADP ratio), closure of ATP-sensitive $\mathrm{K}^{+}\left(\mathrm{K}_{\mathrm{ATP}}\right)$ channels, depolarization of the $\beta$ cell membrane, and opening of the voltage-dependent $\mathrm{Ca}^{2+}$ channels (VDCCs), thereby allowing $\mathrm{Ca}^{2+}$ influx (8). The resultant rise in intracellular $\mathrm{Ca}^{2+}$ concentration $\left(\left[\mathrm{Ca}^{2+}\right]_{i}\right)$ in the $\beta$ cell triggers insulin secretion. In addition to this $\mathrm{K}_{\mathrm{ATP}}$ channel-dependent pathway, which triggers GSIS, there is also a $\mathrm{K}_{\mathrm{ATP}}$ channel-independent pathway that amplifies the effects of $\mathrm{Ca}^{2+}$ on exocytosis (9) and does not require an additional increase in $\left[\mathrm{Ca}^{2+}\right]$.

\section{Dynamics of insulin secretion}

It is well known that the insulin concentration in the blood oscillates even during postabsorptive periods $(10,11)$. There are two major oscillatory secretion patterns, ultradian oscillations (pulsatile secretion), which have a period of 1-2 hours and may be due to a feedback loop between glucose production and insulin secretion (12), and more rapid oscillations, which have a period of $10-15$ minutes (13). Insulin is more effective at reducing blood glucose levels if it is delivered in pulses rather than continuously (14). Oscillatory insulin secretion has also been detected in vitro in isolated dog pancreas and

Conflict of interest: The authors have declared that no conflict of interest exists. Citation for this article: JClin Invest. 2011;121(6):2118-2125. doi:10.1172/JCI45680. pancreatic islets from dogs (15-17). Thus, oscillation of insulin secretion is likely caused by intrinsic $\beta$ cell mechanisms and modified by exogenous signals such as hormonal and neuronal inputs. Oscillations in $\left[\mathrm{Ca}^{2+}\right]_{\mathrm{i}}$ rather than metabolism in the $\beta$ cell are thought to be the direct cause of these oscillations in insulin secretion (17).

Hyperglycemic clamps and experiments in isolated pancreatic islets have demonstrated that glucose induces insulin secretion in a biphasic pattern: an initial component (first phase), which develops rapidly but lasts only a few minutes, followed by a sustained component (second phase) (18-20). Loss of first-phase secretion and reduced second-phase secretion are characteristic features of type 2 diabetes mellitus (T2DM); it is well known that a decrease in the first phase of GSIS is found in the early stage of T2DM and also in impaired glucose tolerance (IGT) $(18,21)$. Thus, in order to understand the pathogenesis and pathophysiology of these diseases, it is important to clarify the cellular and molecular mechanisms responsible for the alterations in the dynamics of insulin secretion. Biochemical experiments and capacitance measurement have suggested that secretory vesicles generally exist in functionally distinct pools and that sequential release of these pools underlies the dynamically separable components of exocytosis (22). Pancreatic $\beta$ cells contain at least two pools of insulin secretory granules that differ in release competence: a reserve pool (RP), which accounts for the vast majority of granules, and a readily releasable pool (RRP), which accounts for the remaining granules (less than 5\%). The prevailing hypothesis is that the release of RRP granules accounts for the first phase of GSIS, and that mobilization of a subsequent supply of new granules for release by mobilization accounts for the second phase (22).

Recently, investigation of insulin granule dynamics has been refined by use of the total internal reflection fluorescence microscopy (TIRFM) system. TIRFM is a technology that provides a means to selectively excite fluorophores in an aqueous or cellular environment very near a solid surface (within $100 \mathrm{~nm}$ ) without exciting fluorescence from regions farther from the surface. The unique features of TIRFM analysis have enabled numerous applications in biochemistry and cell biology (23-26).

Revising previous models, our group used TIRFM to analyze insulin granule dynamics induced by various stimuli in detail, using primary cultured mouse pancreatic $\beta$ cells (25). In contrast to the findings of Ohara-Imaizumi et al. (27), we found three different modes of insulin exocytosis based on the dynamics of insulin granules: mode 1 , in which predocked granules are immediately fused to the plasma membrane by stimulation (old face); mode 2 , in which 
review series

\section{A Old face}

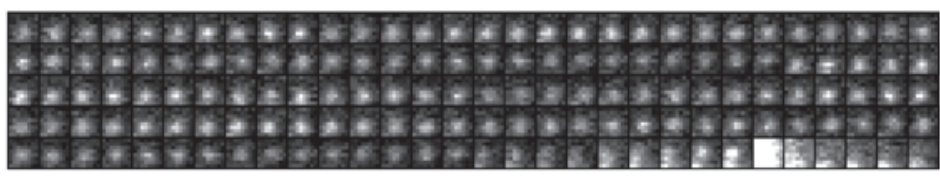

$\begin{array}{rrr}\text { Predocked } & \text { Fusion } & \text { Onsulin granule } \\ & \text { Cell membrane }\end{array}$

B Restless newcomer
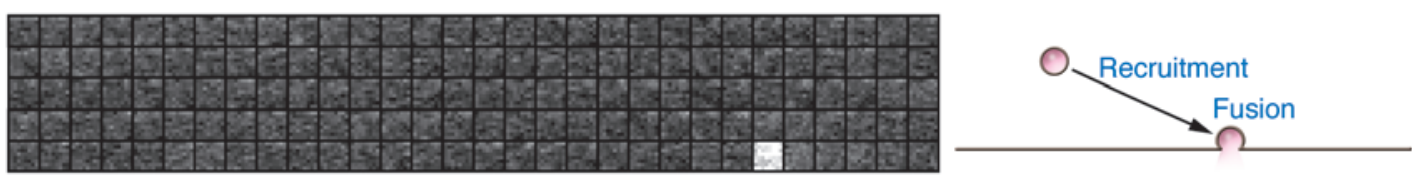

\section{Resting newcomer}
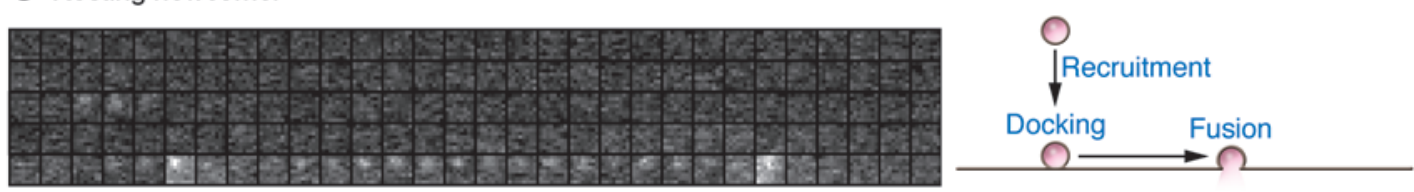

Figure 1

Three modes of insulin granule dynamics. (A) Old face. Predocked granules are fused to the membrane by stimulation. (B) Restless newcomer. Granules are newly recruited and immediately fused to the plasma membrane by stimulation. (C) Resting newcomer. Granules are newly recruited, docked, and fused to the plasma membrane by stimulation. Sequential images $(1 \mu \mathrm{m} \times 1 \mu \mathrm{m})$ acquired every $300 \mathrm{~ms}$ indicate insulin granule dynamics. Flash indicates fusion events of insulin granules. Reproduced from Proceedings of the National Academy of Sciences of the United States of America (25).

granules are newly recruited by stimulation and immediately fused to the plasma membrane (restless newcomer); and mode 3 , in which granules are newly recruited by stimulation but are first docked and then fused to the plasma membrane (resting newcomer) (Figure 1 and ref. 25). Our group further demonstrated a biphasic pattern of glucose-induced insulin granule exocytosis, and found that both phases of glucose-induced insulin granule exocytosis are caused primarily by restless newcomer (25). In contrast, most potassiuminduced insulin granule exocytosis that occurs immediately and transiently after stimulation results from release by old face. This was confirmed by sequential stimulation by glucose and potassium using two protocols: first, glucose stimulation followed by potassium stimulation, and then the reverse (28).

The difference in the granules involved in the first phase of glucose-induced fusion events and those involved in potassiuminduced fusion events is noteworthy. Our group recently demonstrated that interaction of $\operatorname{Rim} 2 \alpha$ with the vesicle protein Rab3 is required for docking of insulin granules but not for either potassium-induced or glucose-induced insulin granule exocytosis (29). Docking is considered to be a braking state that prevents the fusion of granules to the plasma membrane $(26,29)$. Stimulation of pancreatic $\beta$ cells with high concentrations of potassium induces supraphysiologic levels of $\left[\mathrm{Ca}^{2+}\right]_{i}$ that can force insulin granule exocytosis by overwhelming the braking state. We hypothesize that glucose stimulation may not elicit fusion events by old face because the rise in $\left[\mathrm{Ca}^{2+}\right]_{\mathrm{i}}$ induced by glucose is insufficient to overwhelm the braking state, in contrast to that induced by potassium. While potassium-induced insulin secretion requires only the $\mathrm{Ca}^{2+}$ signal, glucose-induced insulin secretion requires $\mathrm{Ca}^{2+}$ and other signals including metabolites (30), permitting different modes of insulin granule exocytosis induced by the two stimuli.
Based on these data, we propose a new model of GSIS, in which both the first and second phases are caused by newly recruited granules without docking (restless newcomer) (Figure 2). These granules are more than $50 \mathrm{~nm}$ away from the plasma membrane but are readily releasable. Although both phases of insulin secretion are caused by these granules, the mechanisms of the first and second phases of insulin secretion are distinct, and the two phases are caused by granules of separate pools. It is known that the actin cytoskeleton is a highly dynamic and complex structure that is remodeled in response to various stimuli (31), and the dynamics of insulin granules by glucose stimulation could also be affected by actin remodeling. Indeed, glucose stimulation triggers transient F-actin remodeling to allow access to the plasma membrane $(32,33)$. Since most insulin granules reside in a region deeper than the F-actin barrier, and F-actin remodeling could mobilize granules to t-SNARE proteins at the plasma membrane (34), it is likely that actin remodeling is involved in the second phase of GSIS. Moreover, a recent study found that inhibition of RhoGDI enhanced the second phase of GSIS through activation of Cdc42 (35). The finding that $\mathrm{Cdc} 42$ promotes actin polymerization (36) further supports the hypothesis that dynamics of the actin network regulate the second phase of GSIS. However, the role of F-actin in the first phase of insulin secretion is still unknown, and it is possible that the roles of the actin cytoskeleton differ in the first and second phases of insulin secretion.

Some insulin granules are known to partially fuse to the plasma membrane, release small molecules, and then undergo endocytosis (termed "kiss-and-run exocytosis") $(37,38)$. However, since crystallized insulin cannot pass the small pore formed by kiss-and-run exocytosis, the full fusion of granules is required for the release of insulin (39). The interaction of insulin granules with VDCC, which 
A Existing model

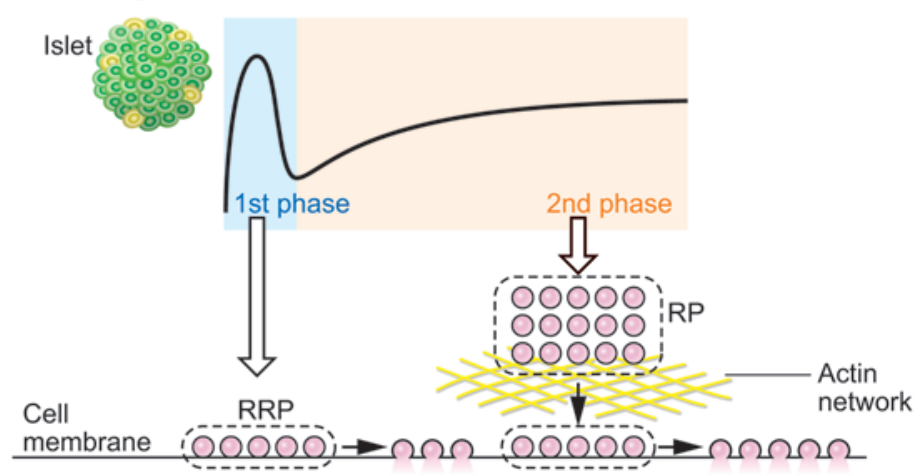

B New model

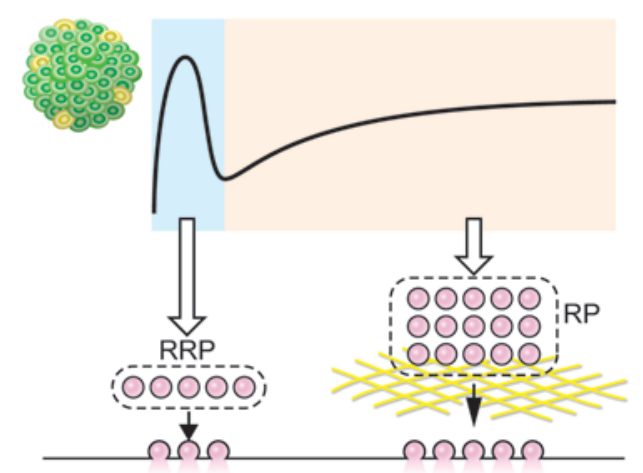

Figure 2

Existing and new models of GSIS in the normal state. (A) In the existing model of GSIS, the first phase of insulin secretion results from a RRP composed of docked insulin granules (old face); the second phase of secretion results from a RP composed of granules located farther away (resting newcomer) that are newly recruited upon stimulation, docked, and fused to the plasma membrane. (B) In the new model, both phases consist of insulin granules that are recruited upon stimulation and immediately fused to the plasma membrane (restless newcomer). A RRP responsible for the first phase is located more than $50 \mathrm{~nm}$ from the plasma membrane, yet is immediately releasable. The second phase of insulin secretion involves exocytosis of insulin granules from a RP associated with the cortical actin network regulated by glucose-evoked signals in a mechanism yet to be elucidated.

promotes the local increase of $\left[\mathrm{Ca}^{2+}\right]_{\mathrm{i}}$ at the fusion site, is proposed to be involved in the full fusion (38).

\section{Regulation of dynamics of insulin secretion by cAMP signaling}

It is well known that the insulin secretory response is much greater after oral than after i.v. glucose administration, even when plasma glucose levels are matched. This phenomenon, called the "incretin effect," is mediated by two gastrointestinal hormones, GLP-1 and GIP (40). GLP-1 and GIP are released in response to the ingestion of nutrients from gastrointestinal endocrine L cells and K cells, respectively (41). Both of these hormones potentiate GSIS $(42,43)$ by activation of cAMP signaling in pancreatic $\beta$ cells (44-46). cAMP acts in the insulin secretory process at various steps $(1,47,48)$. In normal mouse pancreatic islets, in vitro concentration dependency of GSIS displays a sigmoid curve (49), in which glucose concentration exceeding $6 \mathrm{mM}$ is required for triggering insulin secretion. GLP-1 and GIP are known to potentiate both the first and second phases of GSIS from perfused pancreas (50). In addition, it has been reported that although single $\beta$ cells dispersed from rat pancreatic islets are often found to be glucose-insensitive, as assessed by electrical activity, GLP-1 endows these cells with glucose competency, probably by modulating $\mathrm{K}_{\mathrm{ATP}}$ channel activity (51). These findings suggest a mechanism by which cAMP induces glucose responsiveness of pancreatic $\beta$ cells. We recently reported that small and stepwise increases in the glucose concentration from 2.8 to $12.5 \mathrm{mM}$ do not trigger insulin secretion from perfused mouse pancreas (48). However, in the presence of the cAMP analog 8-Br-cAMP or GLP-1, insulin secretion is readily evoked in response to such small increases in glucose concentration. Thus, cAMP signaling is critical not only for potentiation of GSIS, but also for induction of glucose responsiveness. Treatment with GLP-1 induces a delayed but mea-

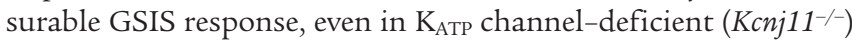
mice (47), indicating that some of the effect of GLP-1 in induction of glucose responsiveness is independent of the $\mathrm{K}_{\mathrm{ATP}}$ channels. In contrast, induction of glucose responsiveness by GIP in $\mathrm{Kcnj11^{-/ }}$ mice is much less than that by GLP-1, which indicates that the action of GIP is critically dependent on $\mathrm{K}_{\mathrm{ATP}}$ channels (47). Differ- ential effects of GLP-1 and GIP on insulin secretion are also found in a clinical setting. For example, treatment with GLP-1 improves insulin secretion in T2DM, whereas GIP does not (52). These and other data suggest that cAMP signaling in distinct intracellular compartments mediates the distinct cellular responses in pancreatic $\beta$ cells (53). Interestingly, a recent study showed that the mouse $\beta$ cell line MIN6-K20, which does not exhibit either GLP-1 or GIP responsiveness in monolayer culture, clearly exhibits responsiveness almost comparable with that of normal mouse islets when pseudoislets (exhibiting three-dimensional structure) are formed by the cell line. These data suggest that $\beta$ cell $-\beta$ cell interaction is critical for induction of cAMP responsiveness (54).

\section{Role of cAMP signaling in insulin granule dynamics}

Although cAMP potentiates GSIS, how cAMP acts in the exocytotic processes of recruitment, docking, and fusion of secretory granules is not clear. Our group has examined regulation of insulin granule dynamics by cAMP signaling using the TIRFM system (25). 8-Br-cAMP alone did not increase the number of docking granules or elicit fusion events but clearly potentiated both the first and second phases of glucose-induced insulin granule exocytosis. 8-Br-cAMP enhanced the exocytosis by increasing the number of restless newcomers, suggesting that activation of cAMP signaling increases the size of the pools (both RRP and RP) of insulin granules and/or facilitates recruitment of insulin granules from the pools to the plasma membrane.

It has been shown that cAMP oscillations occur in pancreatic $\beta$ cells (55-57). A close temporal and causal interrelationship between the increase in cytoplasmic $\mathrm{Ca}^{2+}$ and cAMP levels following membrane depolarization has been reported $(55,56)$. A recent study demonstrated that glucose metabolism directly controls cAMP signaling (57), suggesting that cAMP oscillations regulate dynamics of insulin granule exocytosis.

\section{Role of Epac2A/Rap1 signaling in the regulation of dynamics of insulin secretion}

cAMP regulates the potentiation of insulin secretion by a PKAdependent mechanism and by a PKA-independent mechanism 


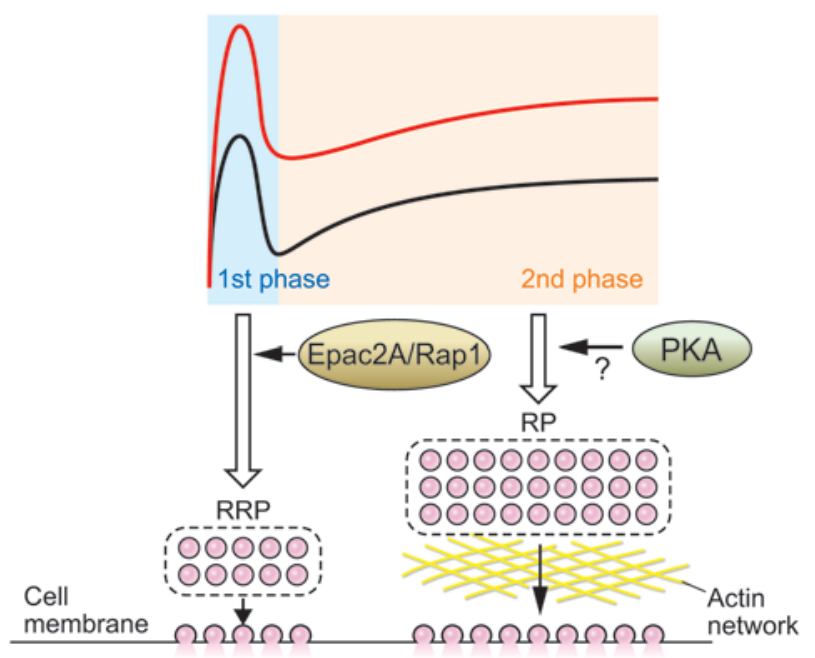

Figure 3

Effect of cAMP signaling on the dynamics of insulin secretion. Activation of cAMP signaling enhances both the first and the second phases of GSIS. Epac2A/Rap1 signaling increases the size of a RRP near the plasma membrane. Whether Epac2A/Rap1 quantitatively or functionally increases the size is not known. The mechanism of potentiation of the second phase of GSIS by cAMP is still unclear, but PKA may be involved in regulating the size of the RP. The black line indicates dynamics of insulin secretion by glucose stimulation, whereas the red line indicates potentiation of GSIS by CAMP signaling.

that involves the cAMP-binding protein Epac2 (now called Epac2A) (6, 58-63). Although there is no defect in the dynamics of glucose-induced insulin granule exocytosis in Epac2a $a^{-/-}$mice, potentiation by cAMP of the first phase of glucose-induced exocytosis was significantly impaired (25). In addition, Rap1, which is activated by cAMP specifically through Epac2A in pancreatic $\beta$ cells, was found to be required for PKA-independent, cAMPpotentiated insulin secretion. Thus, Epac2A/Rap1 signaling is important for the potentiation by cAMP of the first phase of GSIS. A simulation model of insulin granule exocytosis (25) suggests that Epac2A/Rap1 signaling promotes insulin granule exocytosis by increasing the size of an RRP near the plasma membrane (Figure 3).

\section{Epac2A is an intracellular target of sulfonylureas}

Sulfonylureas (SUs), widely used drugs in diabetes treatment, stimulate insulin secretion by closing the $\mathrm{K}_{\mathrm{ATP}}$ channels in the pancreatic $\beta$ cell membrane through binding to the SU receptor SUR1, a regulatory subunit of the channels (64-66).

Epac2A is a direct intracellular target of SUs, as demonstrated in a fluorescence resonance energy transfer-based assay $(67,68)$. Moreover, SU-stimulated insulin secretion is significantly reduced both in vitro and in vivo in mice lacking Epac2a (67). These data indicate that in addition to closure of the $\mathrm{K}_{\mathrm{ATP}}$ channels, which is a prerequisite for $\mathrm{SU}$ action, activation of Epac2A/Rap1 signaling is required for SUs to exert their effects on insulin secretion. Considering the role of Epac2A/Rap1 signaling in insulin granule exocytosis described above, SUs may well increase the size of a RRP of insulin granules near the plasma membrane that is primarily responsible for the early phase of insulin secretion. In fact, SUs are known to stimulate the first phase of GSIS (69).
It has been proposed that SUs also bind to a putative receptor expressed on insulin granules (gSURs) and that gSURs couple with the granular chloride channel ClC-3 (70-72). Acidification of insulin granules enhanced by ClC-3 might facilitate GSIS in pancreatic $\beta$ cells (73-75).

\section{Clinical implications of dynamics of insulin secretion}

Obesity and insulin resistance. Clinically, obesity is characterized by insulin resistance and hyperinsulinemia. Hyperinsulinemia results from increased insulin secretion, decreased insulin clearance (particularly hepatic insulin extraction), or a combination of these two factors (76-79). One study indicates that insulin secretion is increased in moderate obesity under basal conditions over a 24-hour period on a mixed diet and in response to i.v. glucose and is highly correlated with BMI, while hepatic insulin clearance does not differ in normal and obese subjects, suggesting that increased insulin secretion is the major determinant of hyperinsulinemia (78). However, in patients with more marked basal hyperinsulinemia and during intense stimulation of insulin secretion, a reduction in insulin clearance also contributes to the greater increase in peripheral insulin concentrations $(78,79)$.

Because insulin secretion is related to insulin sensitivity $\left(\mathrm{S}_{\mathrm{I}}\right)$ as a hyperbolic function $(80,81)$, compensation of insulin secretion for $\mathrm{S}_{\mathrm{I}}$ is usually estimated from the disposition index (DI), which is calculated as the product of $S_{I}$ and the first-phase acute insulin secretory response to i.v. glucose (AIRg), using the frequently sampled i.v. glucose tolerance test (ref. 82 and Figure 4). It has been shown that $S_{I}$ progressively and significantly decreases with obesity, whereas AIRg rises, and thus DI declines significantly among obese family members (83). A study of obese youth with normal glucose tolerance, IGT, and T2DM indicated that the first-phase insulin response to glucose and DI progressively decrease with the degree of impairment of glucose tolerance, with a more profound defect in obese subjects with T2DM involving both the first- and second-phase insulin responses (84). In addition, because the early-phase insulin secretory defect is not found in subjects with simple obesity (obesity in the absence of metabolic syndrome) and progressive decline of glucose tolerance is only seen in subjects with decreased insulin secretion (85), the glucose intolerance would seem to be evoked not by obesity itself but by the insulin secretory defect, especially in the first phase.

The temporal pattern of insulin secretion and the secretory pulses that occur every 1.5-2 hours in normal subjects are maintained in obese subjects, although the amplitude of these pulses postprandially is greater in obese subjects (78). Rapid oscillations also occur in obese subjects with a periodicity similar to that of normal subjects (10-12 minutes). Thus, the intrinsic regulatory mechanism of the dynamics of insulin secretion appears to be normal in an obese state, and the increase in insulin secretion in obese subjects is not likely due to hyperresponsiveness to various stimuli in individual $\beta$ cells but rather to the larger functional $\beta$ cell mass (Figure 5A).

In a mouse model with $\beta$ cell-specific disruption of the insulin receptor, loss of acute-phase insulin secretion in response to glucose but not to arginine (86) suggests that insulin signaling in pancreatic $\beta$ cells itself is critical to GSIS. In humans, extreme insulin resistance syndrome associated with a primary defect in insulin signaling due to mutations of the insulin receptor gene has been reported (87). Lack of insulin signal transduction in the peripheral tissues is responsible for the continuous elevation of plasma glucose levels after glucose challenge. However, these patients show hyperinsulinemia following glucose stimulation despite the defect in insulin signaling in the 


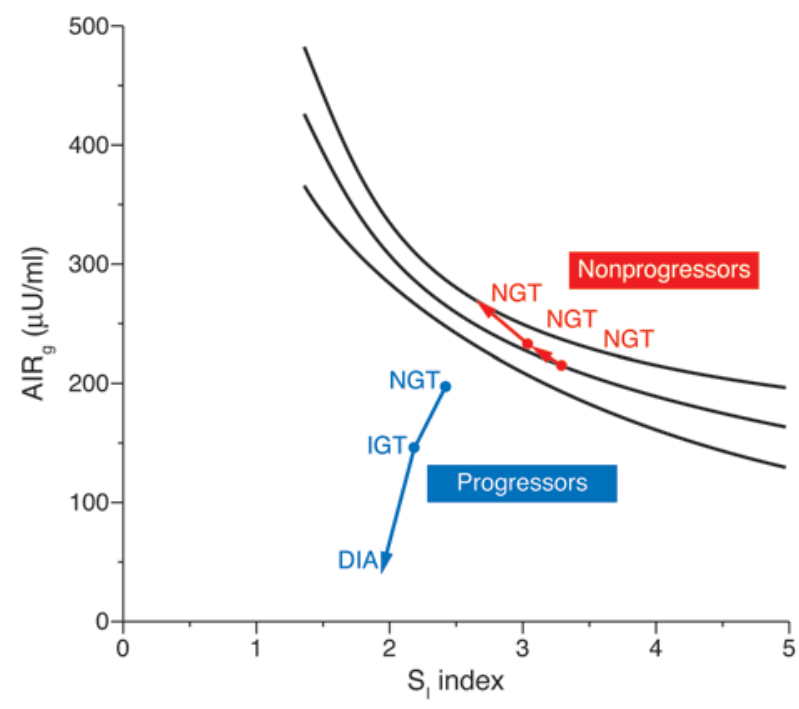

$\beta$ cells (88). Thus, the significance of insulin signaling in human $\beta$ cells in the dynamics of acute insulin secretion remains unclear.

T2DM. T2DM is characterized by impaired insulin secretion and/or insulin resistance. However, insulin secretory capacity is the major factor contributing to the development of T2DM because neither hyperglycemia nor glucose intolerance develops in insulin-resistant patients, so long as sufficient insulin is secreted from $\beta$ cells in a timely fashion in response to various stimuli. Genetic variation between populations likely contributes to differences in insulin secretory capacity, and thus to the proclivity to develop T2DM. For example, although obesity (defined by a BMI of greater than 30) is less prevalent in Japan than the US, the prevalence of T2DM is similar in both countries (89).

\section{Figure 4}

Changes in AIRg relative to changes in $\mathrm{S}_{\mathbf{I}}$ index in Pima Indian subjects in whom glucose tolerance deteriorated from normal glucose tolerance (NGT) to impaired glucose tolerance (IGT) to diabetes (DIA) (progressors) and in subjects who retained NGT (nonprogressors). Lines represent the prediction line and the lower and upper limits of the $95 \%$ confidence interval of the regression between AIRg and $\mathrm{S}_{\text {I }}$ index, as derived from a reference population of Pima Indians with NGT. Adapted from Journal of Clinical Investigation (82).

In addition, Welch et al. reported that all patients with T2DM in a European population exhibited decreased $\mathrm{S}_{\mathrm{I}}(90)$, whereas Taniguchi et al. found that $S_{I}$ in Japanese T2DM is distributed from low to high values (91). In contrast, AIRg was decreased in Japanese patients with T2DM, while AIRg in those of European descent varied.

Impaired insulin secretion may be due to $\beta$ cell dysfunction, reduced $\beta$ cell mass, or both. Whether $\beta$ cell dysfunction or reduced $\beta$ cell mass precedes clinical onset of diabetes remains an open question. However, in mice, surgical and chemical reductions of $\beta$ cell volume demonstrate that the functional adaptation of the normal $\beta$ cell prevents a rise in fasting glucose or reduction in the first phase of insulin secretion $(92,93)$, suggesting that $\beta$ cell dysfunction, rather than a decrease in $\beta$ cell mass, is likely to be more closely associated with the pathophysiology of T2DM.

The insulin secretory response to glucose has been studied using i.v. bolus glucose administration and hyperglycemic clamp, the former suitable for evaluation of the early phase (first phase) of insulin secretion, the latter suitable for evaluation of the second phase $(94,95)$. The first phase of AIRg (81) is often used to evaluate $\beta$ cell function. As mentioned above (and shown in Figure 4), AIRg is related to the degree of $S_{I}$ as a hyperbolic function $(81,82)$. It is accepted that abnormal dynamics of insulin secretion selec-

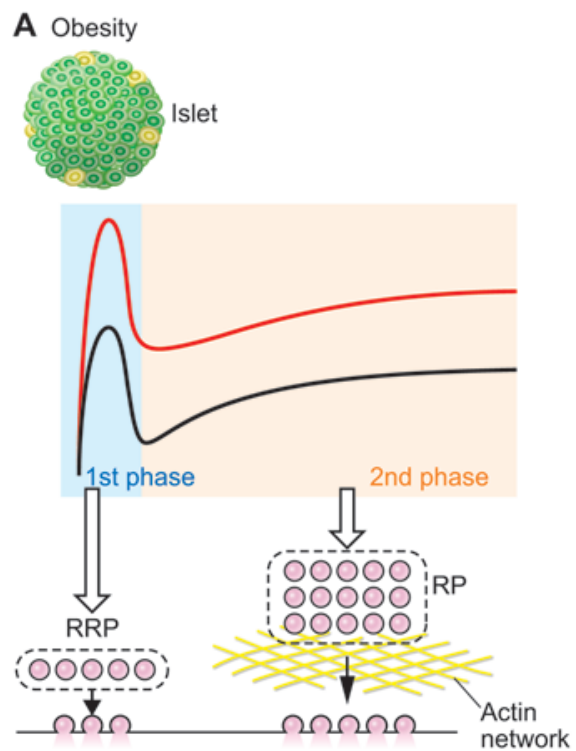

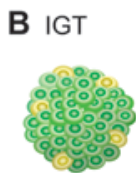

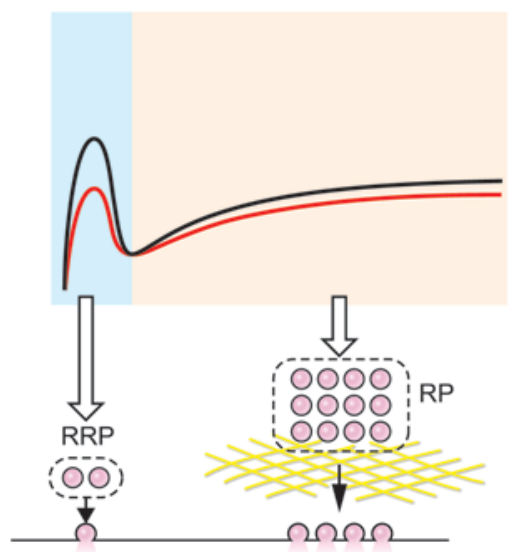

C T2DM

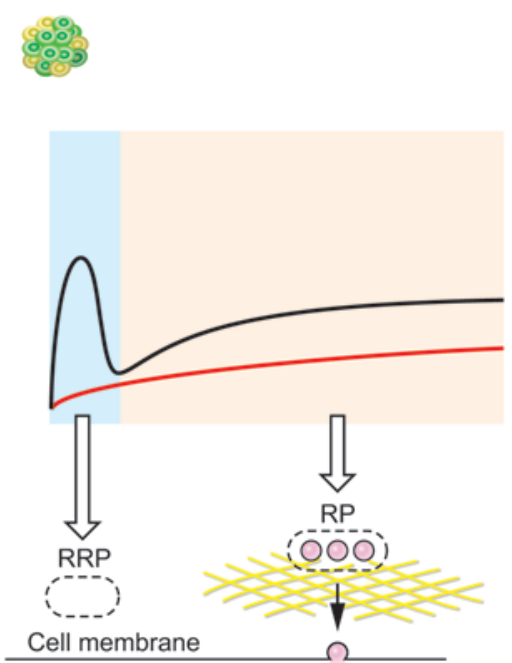

\section{Figure 5}

Dynamics of insulin secretion in obesity, IGT, and T2DM. (A) In obesity, the function of individual $\beta$ cells appears to be normal and both phases of GSIS are enhanced primarily due to an increase in $\beta$ cell mass. (B) In IGT, the first phase is slightly impaired because of a decrease in the size of the RRP and/or partial defect in the exocytotic process of the granules in this pool, and the second phase is only moderately reduced. (C) In T2DM, the first phase is absent because of a complete loss of the RRP and/or a complete defect in the exocytotic process. The second phase is also reduced, probably due to the decreased RP and/or disturbance of cortical actin network in T2DM. Black lines indicate dynamics of insulin secretion in normal state, whereas red lines indicate insulin secretion in disease. 
tive for glucose stimulation, especially the first phase of the insulin response to i.v. glucose, is already reduced in the early stages of T2DM $(96,97)$, first-degree relatives of patients with T2DM (98, 99), and those with IGT and their first-degree relatives (91, 100, 101). In addition, even across the range of normal fasting glucose levels, the first-phase response decreases as the glucose level increases $(97,102)$. Furthermore, as glucose tolerance decreases, for any degree of $\mathrm{S}_{\mathrm{I}}$, the first-phase response is lower in those with lower glucose tolerance (97). As mentioned above, since the early phase of insulin secretion is determined by the RRP, a reduction in its size and/or impaired exocytosis of RRP granules might develop in IGT and in the early stages of T2DM (Figure 5B). The RRP is completely depleted, and the RP is markedly reduced in the developed stage of T2DM (Figure 5C). Signaling mechanisms underlying exocytosis of insulin granules from the RRP and the RP may also be defective in T2DM. Clarification of the mechanisms regulating insulin granule exocytosis from the RRP as well as the size of RRP should be helpful for understanding a defect in the first phase of GSIS in T2DM.

The pulsatile nature of insulin secretion is maintained in patients with T2DM, with the number of pulses similar to that in healthy control subjects (103). Pulses are detected even in patients with very low rates of insulin secretion, suggesting that this rhythmic secretion is a fundamental characteristic of $\beta$ cell function that is retained even when there is a severe loss of secretory reserve (103). However, in patients with T2DM, the pulses after meals are less frequent, are irregular, and have a significantly lower amplitude, resulting in a marked disruption in the dynamics of post-meal insulin secretion. Interestingly, pulsatility and/or rapid oscillation of insulin secretion is lost or disordered in first-degree relatives of T2DM patients who show minimal glucose intolerance or normal glucose tolerance, and subjects with IGT (104-107). A loss of coordinated insulin secretory responses to oscillatory glucose infusion is found in subjects with IGT, indicating a defect in the ability of the $\beta$ cell to properly sense and respond to parallel changes in the plasma glucose level (107). Moreover, a recent mouse study revealed that the molecular clock in $\beta$ cells has a role in rhythmic control of insulin secretion and that ablation of the pancreatic clock can trigger the onset of T2DM (108). These findings suggest that abnormalities in the dynamics of insulin secretion are an early manifestation of $\beta$ cell dysfunction that precedes the development of T2DM.

\section{Effects of incretins and incretin-related drugs on the dynamics of insulin secretion}

The incretin effect is estimated to underlie approximately $60 \%-70 \%$ of insulin secretion in response to glucose in normal healthy subjects (109). Studies using hyperglycemic clamps and i.v. bolus glucose administration indicate that incretin-related agents including GLP-1, GIP, the GLP-1 receptor agonist exenatide, and the GLP-1 analog liraglutide augment both the first and second phases of the insulin secretory response to glucose, with the most predominant effect on the first phase (110). The timing of administration results in differential effects of incretins or incretin-related drugs on the dynamics of insulin secretion $(110,111)$. Although the effects of i.v. infusion of GLP-1 and GIP on potentiation of insulin secretion in response to glucose are similar (112) and additive in normal healthy subjects (113), they have distinct insulinotropic effects in T2DM. GLP-1 infusion can readily normalize hyperglycemia in patients with T2DM (114). On the other hand, the insulinotropic effect of GIP is markedly impaired in patients with T2DM, and GIP infusion in diabetic patients elicits just $40 \%$ of the normal insulin secretory response (109, 114-116). Acute i.v. infusion of GLP-1 (110), liraglutide (117), and exenatide (118) improves insulin secretory response to i.v. glucose in patients with relatively mild T2DM by enhancing both the first and second phases of insulin secretion. The first phase of the insulin response is also improved in patients with T2DM after treatment with liraglutide for 14 weeks, as assessed by i.v. glucose tolerance test. Interestingly, in patients with T2DM, the defect in amplification of the second-phase insulin response to glucose by GIP is more pronounced than that in amplification of the first phase (119). Thus, although both GLP-1 and GIP act on insulin secretion through cAMP signaling in pancreatic $\beta$ cells as described above, these hormones have distinct effects on the dynamics of GSIS.

In vitro, the dynamics of GSIS are usually assessed by a large and rapid increase in glucose concentration, e.g., an immediate increase from 3-4 mM to 16-20 mM glucose. However, such a drastic change in glucose concentration is unlikely to occur in the physiological state in vivo. As described above, although small and stepwise increases in the glucose concentration do not trigger insulin secretion in perfused pancreas, activation of cAMP signaling evokes insulin secretion even in this setting (45). Thus, in addition to potentiation of GSIS, incretins and incretin-related drugs might contribute to triggering the first phase of GSIS in the physiological state in vivo, since circulating levels of GLP-1 and GIP rise concomitantly with blood glucose after meal ingestion.

\section{Conclusion}

Since the first report of biphasic insulin secretion in response to glucose by Curry et al. (19), the dynamics of insulin secretion have been studied extensively in both normal and disease states such as diabetes and obesity using in vitro and in vivo systems. It is generally accepted that the abnormalities in the dynamics of insulin secretion, especially a defect in the first phase of GSIS, represent an early event in the development of T2DM. While studies so far have focused primarily on phenomenology of the dynamics of insulin secretion, the underlying cellular and molecular mechanisms can now be investigated by various approaches. Clarification of these mechanisms should yield novel therapeutic strategies as well as further understating of the pathogenesis and pathophysiology of obesity and T2DM.

\section{Acknowledgments}

We are grateful to Kenneth Polonsky of the University of Chicago for careful reading of, and helpful suggestions for, the manuscript, and Mitsuo Fukushima of Okayama Prefectural University for helpful discussion. We also thank Grace Honkawa for assistance in the manuscript. This work was supported by a CREST grant from the Japan Science and Technology Agency and Grant-in-Aid for Scientific Research and by a grant for the Global Centers of Excellence Program "Global Center of Excellence for Education and Research on Signal Transduction Medicine in the Coming Generation" from the Ministry of Education, Culture, Sports, Science and Technology. The Obesity Review Series is supported in part by unrestricted educational grants from Merck \& Co. and the Life Sciences Institute of the University of Michigan.

Address correspondence to: Susumu Seino, Division of Diabetes and Endocrinology, Department of Internal Medicine, Division of Cellular and Molecular Medicine, Department of Physiology and Cell Biology, Kobe University Graduate School of Medicine, Kobe 650-0017, Japan. Phone: 81.78.382.5860; Fax: 81.78.382.6762; E-mail: seino@med.kobe-u.ac.jp. 
1. Holst JJ, Gromada J. Role of incretin hormones in the regulation of insulin secretion in diabetic and nondiabetic humans. Am J Physiol Endocrinol Metab. 2004;287(2):E199-E206.

2. Newsholme P, Bender K, Kiely A, Brennan L. Amino acid metabolism, insulin secretion and diabetes. Biochem Soc Trans. 2007;35(pt 5):1180-1186.

3. Keane D, Newsholme P. Saturated and unsaturated (including arachidonic acid) non-esterified fatty acid modulation of insulin secretion from pancreatic $\beta$-cells. Biochem Soc Trans. 2008; 36(pt 5):955-958.

4. Baggio LL, Drucker DJ. Biology of incretins: GLP-1 and GIP. Gastroenterology. 2007;132(6):2131-2157.

5. Winzell MS, Ahrén B. G-protein-coupled receptors and islet function-implications for treatment of type 2 diabetes. Pharmacol Ther. 2007;116(3):437-448.

6. Prentki M, Matschinsky FM. $\mathrm{Ca}^{2+}$, cAMP, and phospholipid-derived messengers in coupling mechanisms of insulin secretion. Physiol Rev. 1987; 67(4):1185-1248.

7. Wollheim CB, Sharp GW. Regulation of insulin release by calcium. Physiol Rev. 1981;61(4):914-973.

8. Ashcroft FM. ATP-sensitive potassium channelopathies: focus on insulin secretion. J Clin Invest. 2005;115(8):2047-2058.

9. Henquin JC. Triggering and amplifying pathways of regulation of insulin secretion by glucose. Diabetes. 2000;49(11):1751-1760.

10. Weigle DS. Pulsatile secretion of fuel-regulatory hormones. Diabetes. 1987;36(6):764-775.

11. Lefebvre PJ, Paolisso G, Scheen AJ, Henquin JC. Pulsatility of insulin and glucagon release: physiological significance and pharmacological implications. Diabetologia. 1987;30(7):443-452.

12. Polonsky KS, Given BD, Van Cauter E. Twentyfour-hour profiles and pulsatile patterns of insulin secretion in normal and obese subjects. J Clin Invest. 1988;81(2):442-448.

13. Lang DA, Matthews DR, Peto J, Turner RC. Cyclic oscillations of basal plasma glucose and insulin concentrations in human beings. NEngl J Med. 1979; 301(19):1023-1027.

14. Matthews DR, Naylor BA, Jones RG, Ward GM, Turner RC. Pulsatile insulin has greater hypoglycemic effect than continuous delivery. Diabetes. 1983;32(7):617-621.

15. Stagner JI, Samols E, Weir GC. Sustained oscillations of insulin, glucagon, and somatostatin from the isolated canine pancreas during exposure to a constant glucose concentration. J Clin Invest. 1980; 65(4):939-942

16. Matthews DR, et al. Greater in vivo than in vitro pulsatility of insulin secretion with synchronized insulin and somatostatin secretory pulses. Endocrinology. 1987;120(6):2272-2278.

17. Gilon P, Ravier MA, Jonas JC, Henquin JC. Control mechanisms of the oscillations of insulin secretion in vitro and in vivo. Diabetes. 2002; 51(suppl 1):S144-S151.

18. Cerasi E, Luft R. The plasma insulin response to glucose infusion in healthy subjects and in diabetes mellitus. Acta Endocrinol (Copenh). 1967;55(2):278-304.

19. Curry DL, Bennett LL, Grodsky GM. Dynamics of insulin secretion by the perfused rat pancreas. Endocrinology. 1968;83(3):572-584.

20. Luzi L, DeFronzo RA. Effect of loss of first-phase insulin secretion on hepatic glucose production and tissue glucose disposal in humans. Am J Physiol. 1989;257(2 pt 1):E241-E246.

21. Davis SN, et al. Proinsulin and insulin concentrations following intravenous glucose challenges in normal, obese, and non-insulin-dependent diabetic subjects. Metabolism. 1993;42(1):30-35.

22. Rorsman P, Renström E. Insulin granule dynamics in pancreatic beta cells. Diabetologia. 2003;46(8):1029-1045

23. Axelrod D. Selective imaging of surface fluorescence with very high aperture microscope objectives. J Biomed Opt. 2001;6(1):6-13.

24. Tsuboi T, Zhao C, Terakawa S, Rutter GA. Simultaneous evanescent wave imaging of insulin vesicle membrane and cargo during a single exocytotic event. Curr Biol. 2000;10(20):1307-1310.

25. Shibasaki T, et al. Essential role of Epac2/Rap1 signaling in regulation of insulin granule dynamics by cAMP. Proc Natl Acad Sci U S A. 2007; 104(49):19333-19338.

26. Kasai K, Fujita T, Gomi H, Izumi T. Docking is not a prerequisite but a temporal constraint for fusion of secretory granules. Traffic. 2008;9(7):1191-1203.

27. Ohara-Imaizumi M, et al. Imaging analysis reveals mechanistic differences between first- and second-phase insulin exocytosis. J Cell Biol. 2007; 177(4):695-705.

28. Seino S, Takahashi H, Fujimoto W, Shibasaki T. Roles of cAMP signalling in insulin granule exocytosis. Diabetes Obes Metab. 2009;11 suppl 4:180-188.

29. Yasuda T, et al. Rim $2 \alpha$ determines docking and priming States in insulin granule exocytosis. Cell Metab. 2010;12(2):117-129.

30. Maechler P, Wollheim CB. Mitochondrial signals in glucose-stimulated insulin secretion in the beta cell. J Physiol. 2000;529 pt 1:49-56.

31. Wilson JR, Ludowyke RI, Biden TJ. A redistribution of actin and myosin IIA accompanies $\mathrm{Ca}^{2+}$-dependent insulin secretion. FEBS Lett. 2001;492(1-2):101-106.

32. Thurmond DC, Gonelle-Gispert C, Furukawa M, Halban PA, Pessin JE. Glucose-stimulated insulin secretion is coupled to the interaction of actin with the t-SNARE (target membrane soluble $\mathrm{N}$-ethylmaleimide-sensitive factor attachment protein receptor protein) complex. Mol Endocrinol. 2003;17(4):732-742.

33. Wang Z, Thurmond DC. Mechanisms of biphasic insulin-granule exocytosis - roles of the cytoskeleton, small GTPases and SNARE proteins. J Cell Sci. 2009;122(pt 7):893-903.

34. Jewell JL, Oh E, Thurmond DC. Exocytosis mechanisms underlying insulin release and glucose uptake: conserved roles for Munc18c and syntaxin 4. Am J Physiol Regul Integr Comp Physiol. 2010;298(3):R517-R531.

35. Wang Z, Thurmond DC. Differential phosphorylation of RhoGDI mediates the distinct cycling of Cdc42 and Rac1 to regulate second-phase insulin secretion. J Biol Chem. 2010;285(9):6186-6197.

36. Malacombe M, Bader MF, Gasman S. Exocytosis in neuroendocrine cells: new tasks for actin. Biochim Biophys Acta. 2006;1763(11):1175-1183.

37. Tsuboi T, Rutter GA. Insulin secretion by 'kiss-andrun' exocytosis in clonal pancreatic islet beta-cells. Biochem Soc Trans. 2003;31(pt 4):833-836.

38. Eliasson L, Abdulkader F, Braun M, Galvanovskis J, Hoppa MB, Rorsman P. Novel aspects of the molecular mechanisms controlling insulin secretion. J Physiol. 2008;586(14):3313-3324.

39. Ma L, et al. Direct imaging shows that insulin granule exocytosis occurs by complete vesicle fusion. Proc Natl Acad Sci U S A. 2004;101(25):9266-9271.

40. Nauck MA. Unraveling the science of incretin biology. Am J Med. 2009;122(6 suppl):S3-S10.

41. Elliott RM, Morgan LM, Tredger JA, Deacon S, Wright J, Marks V. Glucagon-like peptide-1 (7-36)amide and glucose-dependent insulinotropic polypeptide secretion in response to nutrient ingestion in man: acute post-prandial and 24-h secretion patterns. J Endocrinol. 1993;138(1):159-166.

42. Dupre J, Ross SA, Watson D, Brown JC. Stimulation of insulin secretion by gastric inhibitory polypeptide in man. J Clin Endocrinol Metab. 1973; 37(5):826-828.

43. Schmidt WE, Siegel EG, Creutzfeldt W. Glucagonlike peptide- 1 but not glucagon-like peptide- 2 stimulates insulin release from isolated rat pancreatic islets. Diabetologia. 1985;28(9):704-707.
44. Thorens B. Expression cloning of the pancreatic beta cell receptor for the gluco-incretin hormone glucagon-like peptide 1. Proc Natl Acad Sci U S A. 1992; 89(18):8641-8645.

45. Usdin TB, Mezey E, Button DC, Brownstein MJ, Bonner TI. Gastric inhibitory polypeptide receptor, a member of the secretin-vasoactive intestinal peptide receptor family, is widely distributed in peripheral organs and the brain. Endocrinology. 1993;133(6):2861-2870

46. Yasuda K, Inagaki N, Yamada Y, Kubota A, Seino $\mathrm{S}$, Seino Y. Hamster gastric inhibitory polypeptide receptor expressed in pancreatic islets and clonal insulin-secreting cells: its structure and functional properties. Biochem Biophys Res Commun. 1994; 205(3):1556-1562.

47. Miki T, et al. Distinct effects of glucose-dependent insulinotropic polypeptide and glucagon-like peptide- 1 on insulin secretion and gut motility. Diabetes. 2005;54(4):1056-1063.

48. Fujimoto W, et al. Niflumic acid-sensitive ion channels play an important role in the induction of glucose-stimulated insulin secretion by cyclic AMP in mice. Diabetologia. 2009;52(5):863-872.

49. Gembal M, Detimary P, Gilon P, Gao ZY, Henquin JC. Mechanisms by which glucose can control insulin release independently from its action on adenosine triphosphate-sensitive $\mathrm{K}+$ channels in mouse B cells. J Clin Invest. 1993;91(3):871-880.

50. Shima K, Hirota M, Ohboshi C. Effect of glucagon-like peptide- 1 on insulin secretion. Regul Pept. 1988;22(3):245-252.

51. Holz GG 4th, Kühtreiber WM, Habener JF. Pancreatic beta-cells are rendered glucose-competent by the insulinotropic hormone glucagon-like peptide1(7-37). Nature. 1993;361(6410):362-365.

52. Nauck MA, Heimesaat MM, Orskov C, Holst JJ, Ebert R, Creutzfeldt W. Preserved incretin activity of glucagon-like peptide 1 [7-36 amide] but not of synthetic human gastric inhibitory polypeptide in patients with type-2 diabetes mellitus. J Clin Invest. 1993;91(1):301-307.

53. Seino S, Shibasaki T. PKA-dependent and PKA-independent pathways for cAMP-regulated exocytosis. Physiol Rev. 2005;85(4):1303-1342.

54. Iwasaki M, Minami K, Shibasaki T, Miki T, Miyazaki J-I, Seino S. Establishment of new clonal pancreatic $\beta$-cell lines (MIN6-K) useful for study of incretin/ cAMP signaling. J Diabetes Invest. 2010;1(4):137-142.

55. Landa LR Jr, et al. Interplay of $\mathrm{Ca}^{2+}$ and cAMP signaling in the insulin-secreting MIN6 beta-cell line. J Biol Chem. 2005;280(35):31294-31302.

56. Dyachok O, Isakov Y, SÅgetorp J, Tengholm A. Oscillations of cyclic AMP in hormone-stimulated insulin-secreting $\beta$-cells. Nature. 2006; 439(7074):349-352

57. Dyachok O, et al. Glucose-induced cyclic AMP oscillations regulate pulsatile insulin secretion. Cell Metab. 2008;8(1):26-37.

58. Malaisse WJ, Malaisse-Lagae F. The role of cyclic AMP in insulin release. Experientia. 1984; 40(10):1068-1074.

59. Jones PM, Persaud SJ. Protein kinases, protein phosphorylation, and the regulation of insulin secretion from pancreatic beta-cells. Endocr Rev. 1998; 19(4):429-461.

60. Eliasson L, et al. SUR1 regulates PKA-independent cAMP-induced granule priming in mouse pancreatic B-cells. J Gen Physiol. 2003;121(3):181-197.

61. Ozaki N, et al. cAMP-GEFII is a direct target of cAMP in regulated exocytosis. Nat Cell Biol. 2000; 2(11):805-811.

62. Bos JL. Epac proteins: multi-purpose cAMP targets. Trends Biochem Sci. 2006;31(12):680-686.

63. Niimura M, Miki T, Shibasaki T, Fujimoto W, Iwanaga $T$, Seino $S$. Critical role of the N-terminal cyclic AMP-binding domain of Epac2 in its subcellular localization and function. J Cell Physiol. 
2009;219(3):652-658.

64. Inagaki $\mathrm{N}$, et al. Reconstitution of $I_{\text {KATP: an inward }}$ rectifier subunit plus the sulfonylurea receptor. Science. 1995;270(5239):1166-1170.

65. Aguilar-Bryan L, et al. Cloning of the beta cell highaffinity sulfonylurea receptor: a regulator of insulin secretion. Science. 1995;268(5209):423-426.

66. Seino S. ATP-sensitive potassium channels: a model of heteromultimeric potassium channel/receptor assemblies. Annu Rev Physiol. 1999;61:337-362.

67. Zhang CL, et al. The cAMP sensor Epac2 is a direct target of antidiabetic sulfonylurea drugs. Science. 2009;325(5940):607-610.

68. Seino S, Zhang CL, Shibasaki T. Sulfonylurea action re-revisited. J Diabetes Invest. 2010;1:37-39.

69. Groop LC, et al. Effect of sulphonylurea on glucose-stimulated insulin secretion in healthy and non-insulin dependent diabetic subjects: a doseresponse study. Acta Diabetol. 1991;28(2):162-168.

70. Kramer W, Muller G, Geisen K. Characterization of the molecular mode of action of the sulfonylurea, glimepiride, at beta-cells. Horm Metab Res. 1996; 28(9):464-468.

71. Barg S, et al. The stimulatory action of tolbutamide on $\mathrm{Ca}^{2+}$-dependent exocytosis in pancreatic beta cells is mediated by a $65-\mathrm{kDa}$ mdr-like P-glycoprotein. Proc Natl Acad Sci US A. 1999;96(10):5539-5544.

72. Renstrom E, Barg S, Thevenod F, Rorsman P. Sulfonylurea-mediated stimulation of insulin exocytosis via an ATP-sensitive $\mathrm{K}^{+}$channel-independent action. Diabetes. 2002;51(suppl 1):S33-S36.

73. Deriy LV, et al. The granular chloride channel ClC-3 is permissive for insulin secretion. Cell Metab. 2009; 10(4):316-323.

74. Barg S, et al. Priming of insulin granules for exocytosis by granular $\mathrm{Cl}^{-}$uptake and acidification. J Cell Sci. 2001;114(pt 11):2145-2154.

75. Li DQ, et al. Suppression of sulfonylurea- and glucose-induced insulin secretion in vitro and in vivo in mice lacking the chloride transport protein ClC-3. Cell Metab. 2009;10(4):309-315.

76. Faber OK, Christensen K, Kehlet H, Madsbad S, Binder C. Decreased insulin removal contributes to hyperinsulinemia in obesity. J Clin Endocrinol Metab. 1981;53(3):618-621.

77. Meistas MT, Rendell M, Margolis S, Kowarski AA. Estimation of the secretion rate of insulin from the urinary excretion rate of C-peptide. Study in obese and diabetic subjects. Diabetes. 1982; 31(5 pt 1):449-453.

78. Polonsky KS, et al. Quantitative study of insulin secretion and clearance in normal and obese subjects. J Clin Invest. 1988;81(2):435-441.

79. Jones CN, Abbasi F, Carantoni M, Polonsky KS, Reaven GM. Roles of insulin resistance and obesity in regulation of plasma insulin concentrations. $A m$ J Physiol Endocrinol Metab. 2000;278(3):E501-E508.

80. Bergman RN, Phillips LS, Cobelli C. Physiologic evaluation of factors controlling glucose tolerance in man: measurement of insulin sensitivity and betacell glucose sensitivity from the response to intravenous glucose. J Clin Invest. 1981;68(6):1456-1467.

81. Kahn SE, et al. Quantification of the relationship between insulin sensitivity and beta-cell function in human subjects. Evidence for a hyperbolic function. Diabetes. 1993;42(11):1663-1672.

82. Weyer C, Bogardus C, Mott DM, Pratley RE. The natural history of insulin secretory dysfunction and insulin resistance in the pathogenesis of type 2 diabetes mellitus. J Clin Invest. 1999;104(6):787-794.

83. Elbein SC, Wegner K, Kahn SE. Reduced beta-cell compensation to the insulin resistance associated with obesity in members of caucasian familial type 2 diabetic kindreds. Diabetes Care. 2000;23(2):221-227.

84. Bacha F, Gungor N, Lee S, Arslanian SA. In vivo insulin sensitivity and secretion in obese youth: what are the differences between normal glucose tolerance, impaired glucose tolerance, and type 2 diabetes? Diabetes Care. 2009;32(1):100-105.

85. Taniguchi A, et al. Insulin sensitivity, insulin secretion, and glucose effectiveness in obese subjects: a minimal model analysis. Metabolism. 1995; 44(11):1397-1400.

86. Kulkarni RN, Brüning JC, Winnay JN, Postic C, Magnuson MA, Kahn CR. Tissue-specific knockout of the insulin receptor in pancreatic beta cells creates an insulin secretory defect similar to that in type 2 diabetes. Cell. 1999;96(3):329-339.

87. Kahn CR, et al. The syndromes of insulin resistance and acanthosis nigricans. Insulin-receptor disorders in man. NEngl J Med. 1976;294(14):739-745.

88. Schoenle EJ, Zenobi PD, Torresani T, Werder EA, Zachmann M, Froesch ER. Recombinant human insulin-like growth factor I (rhIGF I) reduces hyperglycaemia in patients with extreme insulin resistance. Diabetologia. 1991;34(9):675-679.

89. Mandavilli A, Cyranoski D. Asia's big problem. Nat Med. 2004;10(4):325-327.

90. Welch S, Gebhart SS, Bergman RN, Phillips LS. Minimal model analysis of intravenous glucose tolerance test-derived insulin sensitivity in diabetic subjects. J Clin Endocrinol Metab. 1990;71(6):1508-1518.

91. Taniguchi A, et al. Glucose effectiveness in two subtypes within impaired glucose tolerance. A minimal model analysis. Diabetes. 1994;43(10):1211-1217.

92. Kendall DM, Sutherland DE, Najarian JS, Goetz FC, Robertson RP. Effects of hemipancreatectomy on insulin secretion and glucose tolerance in healthy humans. NEngl J Med. 1990;322(13):898-903.

93. McCulloch DK, et al. Defects in beta-cell function and insulin sensitivity in normoglycemic streptozocin-treated baboons: a model of preclinical insulin-dependent diabetes. J Clin Endocrinol Metab. 1988;67(4):785-792.

94. Rachman J, Gribble FM, Barrow BA, Levy JC, Buchanan KD, Turner RC. Normalization of insulin responses to glucose by overnight infusion of glucagon-like peptide 1 (7-36) amide in patients with NIDDM. Diabetes. 1996;45(11):1524-1530.

95. Fritsche A, Stefan N, Hardt E, Häring H, Stumvoll $M$. Characterisation of beta-cell dysfunction of impaired glucose tolerance: evidence for impairment of incretin-induced insulin secretion. Diabetologia. 2000;43(7):852-858.

96. Brunzell JD, et al. Relationships between fasting plasma glucose levels and insulin secretion during intravenous glucose tolerance tests. J Clin Endocrinol Metab. 1976;42(2):222-229.

97. Utzschneider KM, et al. Impact of differences in fasting glucose and glucose tolerance on the hyperbolic relationship between insulin sensitivity and insulin responses. Diabetes Care. 2006;29(2):356-362.

98. Cnop M, et al. Progressive loss of beta-cell function leads to worsening glucose tolerance in first-degree relatives of subjects with type 2 diabetes. Diabetes Care. 2007;30(3):677-682.

99. Doi K, et al. Decreased glucose effectiveness but not insulin resistance in glucose-tolerant offspring of Japanese non-insulin-dependent diabetic patients: a minimal-model analysis. Metabolism. 1997;46(8):880-883.

100. Cavaghan MK, Ehrmann DA, Polonsky KS. Interactions between insulin resistance and insulin secretion in the development of glucose intolerance. J Clin Invest. 2000;106(3):329-333.

101.Emerson P, et al. Different pathophysiology of impaired glucose tolerance in first-degree relatives of individuals with type 2 diabetes mellitus. Metabolism. 2009;58(5):602-607.

102. Godsland IF, Jeffs JA, Johnston DG. Loss of beta cell function as fasting glucose increases in the non-diabetic range. Diabetologia. 2004;47(7):1157-1166.

103. Polonsky KS, et al. Abnormal patterns of insulin secretion in non-insulin-dependent diabetes mellitus. N Engl J Med. 1988;318(19):1231-1239.

104.Lang DA, Matthews DR, Burnett M, Turner RC. Brief, irregular oscillations of basal plasma insulin and glucose concentrations in diabetic man. Diabetes. 1981;30(5):435-439.

105. O'Rahilly S, Turner RC, Matthews DR. Impaired pulsatile secretion of insulin in relatives of patients with non-insulin-dependent diabetes. NEnglJ Med. 1988;318(19):1225-1230.

106. Schmitz O, et al. Disorderly and nonstationary insulin secretion in relatives of patients with NIDDM. Am J Physiol. 1997;272(2 pt 1):E218-E226.

107. Byrne MM, Sturis J, Sobel RJ, Polonsky KS. Elevated plasma glucose $2 \mathrm{~h}$ postchallenge predicts defects in beta-cell function. Am J Physiol. 1996; 270(4 pt 1):E572-E579.

108. Marcheva B, et al. Disruption of the clock components CLOCK and BMAL1 leads to hypoinsulinaemia and diabetes. Nature. 2010;466(7306):627-631.

109. Holst JJ. The physiology of glucagon-like peptide 1 . Physiol Rev. 2007;87(4):1409-1439.

110.Quddusi S, Vahl TP, Hanson K, Prigeon RL, D'Alessio DA. Differential effects of acute and extended infusions of glucagon-like peptide- 1 on first- and second-phase insulin secretion in diabetic and nondiabetic humans. Diabetes Care. 2003; 26(3):791-798.

111.Meier S, Hücking K, Ritzel R, Holst JJ, Schmiegel WH, Nauck MA. Absence of a memory effect for the insulinotropic action of glucagon-like peptide 1 (GLP-1) in healthy volunteers. Horm Metab Res. 2003;35(9):551-556.

112.Vilsbøll T, Krarup T, Madsbad S, Holst JJ. Both GLP-1 and GIP are insulinotropic at basal and postprandial glucose levels and contribute nearly equally to the incretin effect of a meal in healthy subjects. Regul Pept. 2003;114(2-3):115-121.

113.Elahi $\mathrm{D}$, et al. The insulinotropic actions of glucose-dependent insulinotropic polypeptide (GIP) and glucagon-like peptide-1 (7-37) in normal and diabetic subjects. Regul Pept. 1994;51(1):63-74.

114. Nauck MA, Kleine N, Orskov C, Holst JJ, Willms B, Creutzfeldt W. Normalization of fasting hyperglycaemia by exogenous glucagon-like peptide 1 (7-36 amide) in type 2 (non-insulin-dependent) diabetic patients. Diabetologia. 1993;36(8):741-744.

115. Meier JJ, Nauck MA. Is the diminished incretin effect in type 2 diabetes just an epi-phenomenon of impaired beta-cell function? Diabetes. 2010;59(5):1117-1125.

116. Seino Y, Fukushima M, Yabe D. GIP and GLP-1, the two incretin hormones: Similarities and differences. J Diabetes Invest. 2010;1(1-2):8-23.

117. Chang AM, et al. The GLP-1 derivative NN2211 restores beta-cell sensitivity to glucose in type 2 diabetic patients after a single dose. Diabetes. 2003; 52(7):1786-1791.

118. Fehse F, et al. Exenatide augments first- and second-phase insulin secretion in response to intravenous glucose in subjects with type 2 diabetes. JClin Endocrinol Metab. 2005;90(11):5991-5997.

119.Vilsbøll T, Krarup T, Madsbad S, Holst JJ. Defective amplification of the late phase insulin response to glucose by GIP in obese Type II diabetic patients. Diabetologia. 2002;45(8):1111-1119. 